\title{
XV
}

\section{PROIBICIONISMO E NECROPOLÍTICA: OS DESAFIOS DO SERVIÇO SOCIAL EM TEMPOS DE PANDEMIA*}

Warllon de Souza Barcellos

"E eu digo sim

E eu digo não ao não

E eu digo:

É Proibido proibir

É proibido proibir

É proibido proibir"

(Caetano Veloso, 1964)

\section{Introdução}

No Brasil de hoje, 2020, vivenciamos tempos pandêmicos que deixaram exposta a fragilidade das estruturas de assistência à saúde no país. A pandemia originada pelo vírus SARS-COV-2 assolou um sistema já abalado pelos constantes ataques de um jogo político, cujo interesse visa a ruptura do sistema público de saúde, com intensos ataques à sua eficiência e à já tão sabida política de desinvestimento do SUS. O percurso evolutivo da doença, iniciada no final de 2019, culmina agora num cenário de calamidade, com uma mortalidade de mais de 135 mil brasileiros desde que foram iniciadas as medidas emergenciais de distanciamento e isolamento social, em março deste ano.

Não diferente de outras populações mundiais, o novo vírus chega ao país exigindo ações emergenciais, bem como planejamento e organização, porém nosso cenário de assistência em saúde não comporta a estrutura necessária de combate à disseminação do vírus, isto porque todas as esferas do sistema foram desnudadas, mostrando a precariedade e desvelando o descaso estrutural de gestões

*DOI- 10.29388/978-65-86678-44-4-0-f.387-404 
sem foco, sem prioridades e despreparadas. Desta forma vem-se lutando para dar conta das ações de cuidado à saúde, a despeito dos cruéis golpes de desmantelamento, inclusive anteriores à pandemia, e dos fortes abalos de uma estrutura ainda em vias de construção, que afetaram principalmente as fontes de financiamento, produzindo precariedade e sucateamento. É neste caótico contexto que a pandemia do COVID-19 propagou-se fazendo vítimas não somente a população, mas também o sistema público de saúde.

Assim, o presente estudo busca apresentar como o avanço do proibicionismo no mundo e no Brasil apresenta uma relação com o conceito de necropolítica. A partir da demonstração de que, historicamente, foram criadas diversas iniciativas, seguindo orientações internacionais, para propor políticas sobre drogas com caráter repressor e visando o superencarceramento nos níveis mais pauperizadas da classe trabalhadora, procura-se trazer algumas reflexões teóricas sobre a política de redução de danos e os desafios da atuação do Serviço Social em tempos de pandemia.

\section{Proibicionismo e Necropolítica: breve conceituação}

A criminalização das drogas é um evento seletivo, uma vez que não restringe $o$ acesso a todas as substâncias compreendidas como drogas e, ao mesmo tempo, seleciona um grupo específico de indivíduos para ser punido pelo Estado. Não à toa, a proposta aqui é mostrar a relação direta do conceito de necropolítica com a política proibicionista adotada no Brasil, onde há um Estado extremamente punitivo, excludente e assassino. Porém, este mesmo Estado faz um recorte de classe, raça e território. Atingindo, assim, as camadas mais pobres, vulneráveis e comumente residentes das favelas (RIBEIRO JUNIOR, 2016).

Assim, essa grande massa sobrante é considerada fora da lei, estando excluída também do Direito, ao mesmo tempo em que está nele incluída quando é morta ou presa, ações que, muitas vezes, ocorrem impunemente. Tal quadro de mortes, prisões e criminalização constitui paradigma da necropolítica, uma vez que proporciona uma distribuição racional da morte através de aparatos em torno da 
figura do inimigo social e que garante a impunidade daqueles que geram estas práticas em nome da defesa da sociedade (MBEMBE, 2011).

Dessa maneira, o termo necropolítica tem a ver com regimes de distribuição (desigual) da morte e com as funções assassinas do Estado. Refere-se, pois, a um tipo de política entendida como o trabalho de morte na produção de um mundo que transita no limiar do óbito rotineiro, sendo a sua presença, o que define esse mundo da violência "[...] em que o soberano é aquele que é, como se não fosse, a morte" (MBEMBE, 2011, p. 137).

Neste ponto reside a importância das argumentações de Mbembe (2011), que, ao discutir a necropolítica, busca pensar três questões fundamentais, a saber: contextos em que o estado de exceção se torna normal, ou ao menos não é mais a exceção; contextos em que aquelas figuras de soberania, cujo projeto central é a instrumentalização generalizada da existência humana e a destruição material dos corpos, tratam populações humanas subjugadas como descartáveis ou supérfluas; e também nos contextos em que o poder e o governo se referem ou apelam, de maneira contínua, à emergência e à noção ficcionalizada ou fantasmática do inimigo para beneficiar figuras de soberania (MBEMBE, 2012).

A necropolítica, portanto, surge do desemprego, da desnecessidade de força produtiva, cujo detentor passa a ser renegado para o mercado informal e precário, marginalizado e, consequentemente, criminalizado.

É esse processo de criminalização da pobreza que, devido ao cenário de desigualdade social do Brasil (que ocupa, em 2020, o nono lugar no ranking mundial de desigualdade) (ALMEIDA, 2020), resulta em exemplos jornalísticos como o Caso da menina Ágata. Com 8 anos, foi assassinada em razão de um disparo que partiu da arma de um cabo da Polícia Militar, no Morro da Fazendinha, no Complexo do Alemão.

No Brasil, a força, a brutalidade e a repressão policiais se voltam para onde está o foco da punição e criminalização estatais: os corpos pobres. E o cenário de combate às drogas não é diferente, a seletividade do discurso oficial volta seus dispositivos de controle e poder para a gerência destes mesmos corpos, que não possuem valor 
no capitalismo; é o chamado, na teoria foucaultiana, biopoder (MBEMBE, 2012).

Quando esse exercício de poder político proporciona não apenas obediência, mas distribuição racional da morte em torno da figura do inimigo social, é denominado necropoder ou necropolítica. É a necropolítica a responsável por estabelecer dispositivos de desigualdades, seja nas linguagens, nos corpos ou nas instituições sociais; estas relações de dominação e sujeição é que servirão, como apresentado, de norte para o exercício ou não da punição estatal.

A seletividade da criminalização de uma política de drogas essencialmente proibicionista, por exemplo, é um dos instrumentos de dominação da necropolítica, já que servirá de medidor para a dosagem de vigilância, medicalização, loucura e delinquência de determinado corpo, justificando, assim, a violência estatal que sobre ele se opera.

A eleição de determinado corpo, no entanto, como há de se imaginar, não é discricionária, de forma que os corpos (e mentes) que gerem a necropolítica são determinados. Baseado neste contexto, é que está centralizada a importância do debate apresentado por Mbembe (2011), ao discutir necropolítica. Isso nos faz relembrar alguns episódios clássicos que ocorreram especificamente na Cidade do Rio de Janeiro e que são fundamentais para refletirmos sobre este momento em que a banalização e naturalização das mortes tem sido comum em nosso cotidiano.

Desde a campanha eleitoral de 2018, o Governador afastado por denúcias de corrupção, Wilson Witzel (PSC), já sinalizava declarações do tipo: "a polícia vai mirar na cabecinha e... fogo" ${ }^{1}$. Outro caso clássico ocorreu no ano de 2019, na ponte Rio-Niterói, episódio em que o mesmo comemorava a morte de um sequestrador ${ }^{2}$, descendo de seu helicóptero e comemorando como se fosse o nascimento de uma vida, mas, na verdade, tratava-se da morte de um jovem preto, pobre e favelado que, historicamente, teve sua vida marcada pela au-

\footnotetext{
1 Disponível em: <https://veja.abril.com.br/politica/wilson-witzel-a-policia-vai-mirar-nacabecinha-e-fogo/>. Acesso em: 31 mar..2021.

${ }^{2}$ Disponível em: <https://www.correiobraziliense.com.br/app/noticia/brasil/2019/08/20/interna-brasil,778167/wilson-witzel-comemora-desfecho-com-morte-do-sequestrador-no-riode-ja.shtml>. Acesso em: 31 mar. 2021.
} 
sência de políticas públicas que o permitissem uma outra forma de vida. Casos assim só reforçam o processo de naturalização do extermínio desigual de uma parcela da população.

Vale ressaltar que o proibicionismo vem sendo utilizado como um dispositivo da necropolítica, pois vem servindo como uma ferramenta para justificar os fortes ataques a exclusivos grupos sociais minoritários, como jovens negros periféricos, que são hoje um dos principais alvos de uma política de drogas repressora e punitiva. Dados nos mostram que, hoje, no Brasil, existe um superencarceramento por tráfico de drogas e esses números aumentam significativamente quando falamos do cárcere feminino, muita das vezes associado ao tráfico de drogas.

Ao longo do tempo, a pobreza tem sido criminalizada por parte das forças dominantes em seus mais diferentes cenários. No Brasil, prontamente se constatará que os pobres nunca possuíram uma posição de prestígio na sociedade, quer nobre, quer burguesa. Deste modo, as pessoas têm se habituado, nesse ínterim, a compreendê-la sempre como um mal destinado a impedir o progresso da nação ao nível de países desenvolvidos (BOITEUX, 2006).

No decorrer das décadas, a erradicação da pobreza se tornou o principal objetivo a ser atingido, independentemente de que como seria executada. O fato é que as classes subalternas têm assumido o ponto central de preocupações, caracterizando-se como objeto principal de extinção. Estes indivíduos escolhidos, sobre os quais se discutiu anteriormente e cujas necessidades reais são coibidas, consequentemente, transformam-se em alvo de um ato de violência (estrutural), o qual não é visto desse modo, embora as mais diversas evidências no amplo cenário de injustiças que assolam o Brasil demonstrem isso (POLICARPO, 2018).

No que se refere à mobilização e à organização social, os trabalhadores questionam as suas condições, assim, optando por alterálas, lutando por uma sociedade mais equânime, o que exige uma mudança significativa no modo de produção capitalista. Em contrapartida, a alternativa se refere a um mero incitamento da desordem, a exemplo do traficante, que elabora regras próprias onde o Estado não se faz presente para disciplinar as relações sociais. 
De acordo com Mbembe (2011), apoiado na visão foucaultiana, houve uma passagem da biopolítica, isto é, da gestão da vida e da morte pelo poder (que regulamenta os sujeitos através de dispositivos que visam um conjunto de processos, como a proporção dos nascimentos e dos óbitos, a taxa de reprodução, fecundidade da população) para a regulamentação não mais da vida, mas da morte, por essa razão, denominada necropolítica. As consequências dessa mudança de paradigma levam ao extremismo, visto que "Las tecnologias de destruicion son ahora más tactils, más anotómicas y sensoriales, en um contexto en el que se decide entre la vida y la muerte" - As tecnologias de destruição são agora mais táteis, mais anotômicas e sensoriais, em um contexto em que se decide entre a vida e a morte (MBEMBE, 2011, p. 63, tradução livre).

Dessa maneira, a passagem da biopolítica para a necropolítica acarreta consequências trágicas; as técnicas de exercício de autoridade policial e de disciplina e a eleição entre obediência e hipocrisia são substituídas por alternativas mais trágicas (MBEMEBE, 2011).

Além das prisões e das mortes, o proibicionismo também vem sendo utilizado como dispositivo de necropolítica, uma vez que tem servido para justificar a violência a determinados grupos étnico-raciais, como a juventude negra e periférica, principal vítima da atual política sobre drogas (RIBEIRO JúNIOR, 2016). Não coincidentemente, dados do Conselho Nacional de Justiça (CNJ, 2017) revelaram que um em cada quatro presos foi condenado por roubo ou tráfico de drogas.

\section{Do golpe de Estado de 2016 à Jair Bolsonaro: os ataques a Política de Saúde Mental e Drogas}

Desde o golpe de Estado de abril de 2016, no Brasil, há um novo momento do neoliberalismo, adequado aos desdobramentos da crise do capitalismo que se agudizou nos últimos anos, após o debate de 2008/2009, nos países do capitalismo central. Hoje, estaríamos em uma espécie de retomada da programática mais dura do Consenso de Washington, datado de 1989.

No Brasil, desde junho de 2013, ficaram expostos os limites das gestões petistas e a sua postura assumida de coalizão e de conci- 
liação de classes, que não enfrentaram a reforma política necessária, como a reforma tributária (necessária à taxação de grandes fortunas e propriedades) e a reforma agrária, já que não tiveram coragem política para alterar a rota macroeconômica - que seria a única forma de aprofundar mudanças duradouras para a classe trabalhadora, abrindo caminho para efetivas reformas. O agravante recente foi um ambiente internacional desfavorável desde a eclosão da crise de 2008/2009, nos países centrais, mas cujos impactos maiores chegaram ao Brasil poucos anos depois. O desfecho político dessa erosão, desde a segunda eleição de Dilma, foi o golpe parlamentar midiático com o apoio do judiciário. Essa foi a saída burguesa brasileira para se adaptar ao novo momento do neoliberalismo no mundo e se conectar com as exigências do ambiente internacional, de imensa liquidez de capitais, buscando desesperadamente nichos de valorização e em que a disputa geopolítica acirrada pela recuperação das taxas de lucro promovesse uma ofensiva desenfreada sobre os trabalhadores, o que coloca em xeque os direitos, as políticas sociais que os materializam e a própria democracia (BEHRING e BOSCHETTI, 2008).

Uma das medidas mais representativas deste contexto foi a "marcha da insensatez", que o governo Temer (2016-2018) aliado ao capital colocou em prática a fim de inviabilizar políticas sociais que asseguram direitos, impondo grandes retrocessos por meio da EC (Emenda Constitucional) no 95. Esta faz parte do duro ajuste fiscal adotado por aquele governo, que, popularmente, ficou conhecida como PEC do Fim do Mundo, aprovada em 29 de novembro de 2016, após a devastadora repressão de manifestantes que fizeram uma caravana a Brasília em protesto contra a medida.

Todo o projeto foi tomado de grande polêmica, pois a referida EC, sob a égide da necessidade de se promover uma mudança nos rumos das contas públicas brasileiras, propôs a limitação ao aumento da despesa primária (CÂMARA DOS DEPUTADOS, 2016).

O reflexo dessa limitação é a impossibilidade de aumento real - acima da inflação - no âmbito das contas públicas por 20 exercícios financeiros (CÂMARA DOS DEPUTADOS, 2016). Ademais, e aqui reside a polêmica abordada nesta pesquisa, a Emenda à Constituição (EC) estabelece limites aos gastos no campo da saúde, conforme o 
art. 110 do ADCT (Ato das Disposições Constitucionais Transitórias) da Constituição da República (Emenda à Constituição n. 95):

Art. 110. Na vigência do Novo Regime Fiscal, as aplicações mínimas em ações e serviços públicos de saúde e em manutenção e desenvolvimento do ensino equivalerão: I - no exercício de 2017 , às aplicações mínimas calculadas nos termos do inciso I do § 20 do art. 198 e do caput do art. 212, da Constituição Federal; e II - nos exercícios posteriores, aos valores calculados para as aplicações mínimas do exercício imediatamente anterior, corrigidos na forma estabelecida pelo inciso II do $\S 1$ 으 do art. 102 deste Ato das Disposições Constitucionais Transitórias. (BRASIL, 2016).

A justificativa do Poder Executivo é a deterioração no resultado primário das contas públicas nos últimos anos, gerando um déficit de cerca de $\mathrm{R} \$ 170$ bilhões, se considerado apenas o ano 2016. Nesse sentido, a raiz do problema fiscal brasileiro estaria no crescimento acelerado da despesa primária. No âmbito político, o significado da EC 95/2016 é o avanço do ideário neoliberal para as políticas sociais brasileiras naquilo que outrora foi caracterizado como "crise do Estado".

Fica claro que, com este enxugamento nos investimentos nas políticas sociais e, consequentemente, nas políticas de saúde, saúde mental e de drogas, torna-se importante este debate, uma vez que milhões de brasileiros que dependem destas políticas veem, cada vez mais, o acesso a elas se tornar restrito.

No âmbito da Política Social de Saúde Mental e de drogas alguns pontos se fazem necessário destacar, uma vez que, já desde os governos petistas, passando por Temer (2016-2018), a política vem sofrendo com fortes cortes.

A exemplo das drásticas consequências da EC 95, temos a exemplo a Portaria GM/MS no 3.588, de 21 de dezembro de 2017 (BRASIL, 2017), sancionada no governo Temer (2016-2018), que aumenta o valor da diária de internação paga aos hospitais psiquiátricos e amplia de $15 \%$ para $20 \%$ o número de leitos psiquiátricos nessas unidades; com a promulgação da Lei no 10.216, de 6 de abril de 2001, passa-se a redirecionar o modelo de cuidado em saúde mental, priorizando os serviços comunitários e extra-hospitalares, devendo a in- 
ternação psiquiátrica ser realizada somente como último recurso assistencial, em caráter excepcional, de forma que fica claro que a esta Portaria contradiz o estabelecido pela Lei no 10.216 e, consequentemente, as conquistas obtidas pela Reforma Psiquiátrica e a Luta Antimanicomial (AMARANTE, 2003).

Outro fator foi violado na elaboração desta Portaria, contrariando o que é estabelecido na Lei no 8.142, de 28 de dezembro de 1990, que dispõe sobre a participação da comunidade na gestão do Sistema Único de Saúde (SUS) e cria a Conferência de Saúde enquanto instância colegiada, a se reunir a cada quatro anos com a representação dos vários segmentos sociais, para avaliar a situação de saúde e propor as diretrizes para a formulação da política de saúde nos níveis correspondentes. Vale destacar que a Portaria no 3588, de 21 de dezembro de 2017, foi aprovada pela Comissão Intergestores Tripartite (CIT) sem consulta ou debate com a sociedade civil ou com o Conselho Nacional de Saúde.

Fica claro que a referida normativa apresenta retrocessos à Política Nacional de Saúde Mental e propõe a desestruturação da lógica organizativa da Rede de Atenção Psicossocial, alterando, entre outros pontos: a) A inclusão do hospital psiquiátrico na Rede de atenção Psicossocial (RAPS); b) O aumento do valor da diária de internação em hospitais psiquiátricos; c) O não fechamento do leito com a desinstitucionalização do paciente cronificado ferindo o disposto nas portarias 106/2000, 3090/2011 e 2840/2014; d) O aumento do número de leitos psiquiátricos em hospital geral de $15 \%$ para $20 \%$; e) 0 aumento do número mínimo de 04 para 08 leitos de saúde mental em hospital geral para recebimento de custeio; f) Exigência de taxa de ocupação de $80 \%$ em leitos de saúde mental em hospital geral, como condicionante para recebimento de recursos de custeio; g) 0 retorno de serviços obsoletos, como as unidades ambulatoriais especializadas, quando as equipes do NASF, Saúde da Família e do CAPS poderiam ser incrementadas e ampliadas para atender a esta demanda (BRASIL, 2018).

Foi, então, esta reunião de 21 de dezembro de 2017 da Comissão Intergestores Tripartite (CIT) do Sistema Único de Saúde (SUS) integrada por três partes: Ministério da Saúde, Conselho Nacional dos Secretários de Saúde (Conass) e Conselho Nacionais das Secreta- 
rias Municipais de Saúde (Conasems). De forma intempestiva e nunca vista antes, que a CIT aprovou a "nova" política de saúde mental, de maneira rápida e sem permitir o amplo e necessário diálogo com os órgãos deliberativos que compõem este conselho.

Da maneira como se conduziu a aprovação desta "nova" Política de Saúde Mental, fica claro que o objetivo será atender os interesses econômicos de determinados grupos, como as comunidades terapêuticas e demais que realizam uma defesa ideológica da mentalidade manicomial (ARBEX, 2013). Esta proposta retoma o financiamento dos hospitais psiquiátricos e cria serviços ambulatoriais, deixando de dar a ênfase necessária aos serviços de base territorial e comunitária.

Fica claro que a posição adotada tanto pelo ex-Coordenador Nacional de Saúde Mental, Quirino Cordeiro, quanto pelo ex-ministro da Saúde, Ricardo Barros, fere o princípio constitucional da participação social na gestão da política de saúde, já que tal proposta foi realizada de forma obscura, não permitindo o diálogo entre usuários, familiares e profissionais da Política Nacional de Saúde Mental e Drogas.

As mudanças refletem diretamente na vida dos usuários desta política, tendo em conta que os mesmos deveriam ter sido minimamente ouvidos e tido o direito de opinarem sobre tal, o que não foi realizado. Assim, dentre as alterações significativas realizadas, citamse:

Em primeiro lugar, foi retirada da política a ênfase na reabilitação. Foi retirada também a proposta de trabalho com economia solidária, o que corta uma iniciativa de sucesso e que inclusive tem peso econômico. Em segundo lugar, faz-se um aporte muito substancial de dinheiro público para o "negócio" das comunidades terapêuticas, retornando-se à ênfase dos manicômios com financiamento de leitos de hospitais psiquiátricos e aumento de números de leitos em hospitais gerais, de uma forma que não se permite um cuidado de qualidade.

Tais mudanças nos levam a um caminho de retrocesso, a retirada da ênfase na reabilitação psicossocial e na economia solidária aponta para um caminho de volta a pessoas dependentes, sem incentivo para tornarem-se produtivas, tuteladas e autônomas. 
A ênfase nas internações retrocede aos típicos loucos de manicômios, ociosos, retornando e reforçando a lógica manicomial. A ênfase nas comunidades terapêuticas traz um aporte de dinheiro para estas instituições, muitas delas tendo sido denunciadas como locais de tortura, exploração do trabalho dos usuários e de encarceramento privado. Recentemente, o Conselho Federal de Psicologia lançou o Relatório da Inspeção Nacional em Comunidades Terapêuticas, e, em suas mais de 150 páginas, o presente relatório sistematiza o conjunto de informações coletadas em cada um dos 28 estabelecimentos visitados - em todos, há de se frisar, foram identificadas práticas que configuram violações de direitos humanos.

Considerando a oferta de financiamento público a esse modelo de instituição - inclusive em desfavor das políticas de saúde mental de base comunitária, como consubstanciado na Lei 10.216/2001 (BRASIL, 2001) - o relatório da Inspeção Nacional em Comunidades Terapêuticas evidencia questões, convoca à reflexão e exige uma tomada de posição por parte do Estado e da sociedade brasileira.

O horizonte está na compreensão de que manicômio não se resume aos muros dos antigos e tradicionais hospitais psiquiátricos, mas, muito além disso, constitui uma lógica que se concretiza nas relações humanas, tendo como imperativos a segregação e a anulação de sujeitos (BASAGLIA, 2005).

Ainda no fim de 2017, o governo de Michel Temer (20162018) apresentou e foi aprovada na Comissão Intergestores Tripartite (CIT), em 14 de dezembro de 2017, a Resolução no 32, que reformula a RAPS, incluindo um novo dispositivo assistencial para o campo das drogas, o CAPSad IV, que funcionará 24 hs, com equipes multiprofissionais e que serão localizados em regiões metropolitanas (acima de 500 mil habitantes) próximas às "cracolândias". Contudo, ressalta-se que o Coordenador Nacional da Saúde Mental, na época, sem debater com a instância deliberativa do Conselho Nacional de Saúde (CNS), instituiu a Portaria GM/MS no 3.588, de 21 de dezembro de 2017, que, se respaldando na aprovação da CIT, altera a RAPS, e, além de incluir o dispositivo assistencial acima, adiciona também, com lógica médico-manicomial: Equipe Multiprofissional de Atenção Especializada em Saúde Mental/Unidades Ambulatoriais Especializadas, Unidade de Referência Especializada em Hospital Geral, Hospital 
Psiquiátrico Especializado e Hospital Dia. Assim, esse conjunto de ações políticas foi questionada pelo plenário do CNS, estando a referida Portaria em questão.

Logo, em outra ocasião, mas com a mesma intenção foi apresentada e aprovada uma proposta que endurece a nova política de drogas no Conselho Nacional de Políticas sobre Drogas (CONAD), em 09 de março de 2018, instituída pela BRASIL, 2018. A proposta tem autoria do ex-ministro do Desenvolvimento Social e Agrário, Osmar Terra, médico-psiquiatra, defensor das Comunidades Terapêuticas e da lógica das internações forçadas e crítico ao modelo de redução de danos no combate às drogas. Para ele, a política sobre drogas deve ser orientada para a abstinência, ou seja, que o consumo seja absolutamente proibido e para que as ações do governo se concentrem em pesquisar e tratar a dependência química ou psicológica (BARCELLOS; DUARTE, 2020,. 117).

Suas declarações em geral demonstram seu posicionamento contrário à descriminalização e regulação das drogas, assim como da redução de danos. Sua trajetória política, iniciada no Rio Grande do Sul, é permeada por contradições e denúncias. Além do Projeto de Lei sobre drogas, ele também assinou junto ao deputado e agora presidente Jair Bolsonaro (2019-2022), um projeto que extingue o regime semiaberto nas prisões.

Tal proposta demonstra claramente o despreparo e ilegitimidade deste governo, que não respeita minimamente o direito de escolha de seu usuário. A Política Nacional de Drogas, que vinha assumindo uma postura em favor da política de redução de danos, por entender que a abstinência não pode ser o único objetivo a ser alcançado, agora, constitui-se como resistência, como num passado remoto, no campo da atenção e cuidado aos usuários.

Desta forma, entende-se que se faz necessário proporcionar ao usuário uma educação em direitos humanos sobre drogas, que the permita autonomia para fazer suas próprias escolhas, sendo este um grande desafio. Além disso, quando se trata de seres humanos, temos que, necessariamente, lidar com as singularidades e com as diferentes possibilidades e escolhas que são feitas. As práticas de saúde, em qualquer nível de ocorrência, devem levar em conta tal diversidade. Precisam acolher sem julgamentos cada situação, cada usuário, o 
que é possível e o que é necessário, o que está sendo demandado, e o que pode ser ofertado, sempre estimulando a sua participação e o seu engajamento (BARCELLOS; DUARTE, 2020).

Os movimentos orquestrados no Conad e no Ministério da Saúde parecem frutos da nova vitrine do governo federal: a segurança pública. Segundo Osmar Terra, a aprovação da sua proposta o Projeto de Lei Complementar (PLC) 37 está pronto para ser votado no Senado.

Já em 2019, primeiro ano de governo de Jair Bolsonaro (20192022), começamos em fevereiro sofrendo fortes ataques via Nota Técnica no 11/2019-CGMAD/DAPES/SAS/MS do Ministério da Saúde, que tem por objetivo reorientar as diretrizes da Política Nacional de Saúde Mental. Nesta, constam a compra de aparelhos de eletroconvulsoterapia, eletrochoques para o Sistema Único de Saúde (SUS), internação de crianças em hospitais psiquiátricos e abstinência para o tratamento de pessoas dependentes de álcool e outras drogas, reforçando a lógica proibicionista e descredibilizando a importância de uma política pública de redução de danos. Retira-se, dessa forma, o protagonismo da política de redução de danos, adotada há 30 anos no país, após esforços do movimento de sanitaristas e de luta antimanicomial.

Tais disposições representam um retrocesso na política de saúde pública, por acarretarem o retorno a um modelo arcaico de tratamento, que subtrai o paciente da sua existência e da possibilidade concreta de sociabilidade, lançando-o num espaço de exclusão.

Vale ressaltar que este modelo neoliberal e de ataque a Política de Saúde Mental e Drogas no Brasil, tem por finalidade a imposição de um modelo manicomial, que não é apenas físico, mas sim, aqueles que reforçam as lógicas que segregam, excluem e normatizam, inclusive pelos processos de medicalização, psiquiatrização e psicologização também os são e é o que se assiste no contemporâneo da vida social (DUARTE, 2018). E esses modelos que segregam e excluem, são os mesmos que matam e ceifam vidas, configurando-se, assim, a necropolítica. O avanço do neoliberalismo e os fortes ataques à política de saúde mental e o avanço do proibicionismo só tornam mais evidente a relação do conceito de necropolítica com o Estado neoliberal. 
Baseado neste contexto, fica claro nosso compromisso com a classe trabalhadora, devemos assim, ter por objetivo destacar a liberdade, a emancipação e a defesa dos direitos humanos como pontos convergentes que sinalizam não só para a transformação de práticas, mas também para que seja possível a construção de uma nova ordem societária que não tenha qualquer discriminação, opressão e exploração e supere a propriedade privada dos meios de produção.

De acordo com Duarte (2018), se tomarmos os 200 anos de história do manicômio e do saber psiquiátrico no Brasil, pode-se afirmar que a coexistência dos modelos assistenciais no campo da saúde mental e drogas, manicomial-proibicionista e psicossocial-redução de danos, é um fato político e público contemporâneo. Assim, e embora a Reforma Psiquiátrica esteja ameaçada, em processo de esfacelamento contínuo e progressivo, com previsão de mais e maiores acirramentos políticos, econômicos e éticos no campo mesmo do trabaIho em saúde mental, exigindo dos seus trabalhadores, usuários e familiares, alicerçados pelos princípios da luta antimanicomial e antiproibicionista, é fundamental uma articulação na defesa intransigente do SUS público e a aposta na rede potente, criativa e viva entre esses atores, para, assim, haver resistência nesse contexto de mais uma transição nos marcos econômicos e políticos do sistema capitalista.

\section{A pandemia da COVID 19 e os desafios colocados ao Serviço Social}

No Brasil, as consequências da pandemia do coronavírus, apesar de ainda não dimensionáveis, impactam sobremaneira a vida de toda a população e, consequentemente, a própria organização social, como é o caso das recomendações de isolamento e higienização. Para além das medidas de prevenção ao contágio do COVID19, o Brasil passa, também, por uma crise social, encontrando-se, atualmente, num contexto de desemprego, subemprego, ausência de moradia, abastecimento de água e saneamento básico. Dessa forma, são necessárias também políticas públicas e medidas governamentais que se prestem à contenção e solução de tais questões, em especial aquelas que se voltem aos já mencionados níveis mais vulneráveis da 
sociedade (catadores de lixo, trabalhadores, populações ribeirinhas, pescadores artesanais, empregadas domésticas e diaristas, camelôs, etc) (JUNQUEIRA e TEJADAS, 2021).

Os assistentes sociais brasileiros têm sua atuação profissional marcada em diversos espaços sócio ocupacionais e nas mais diferentes áreas, como saúde, assistência social, previdência, sociojurídico e outras. Muitos profissionais tiveram a oportunidade de se isentar do trabalho ou desenvolver as suas atividades laborativas de forma remota. Porém, devido à crescente onda de avanço da pandemia da COVID 19 a orientação de secretarias estaduais e municipais e de Ministérios, para os profissionais atuantes na linha de frente (incluindo os assistentes sociais), tem sido exatamente no sentido de adiamento de férias, licenças e quaisquer tipos de ausência do trabalho, exceto nos casos de trabalhadores idosos, portadores de doenças autoimunes ou crônicas, diabetes, hipertensão, grávidas ou lactantes (JUNQUEIRA e TEJADAS, 2021).

Há que se considerar, no entanto, que a necessidade de se efetivar direitos como a seguridade social pública e a saúde no Brasil passa pela articulação entre a implementação de políticas públicas e sociais (sejam estas de saneamento, de habitação, de previdência ou de trabalho e renda), o que demanda não apenas a atuação de assistentes sociais ou de profissionais da saúde, mas exige também, latentemente, a revogação da EC no 95, a fim de possibilitar a liberação de um maior volume orçamentário, trazendo de volta os $\mathrm{R} \$ 7$ bilhões retirados da saúde entre os anos de 2017 e 2018 (JUNQUEIRA e TEJADAS, 2021).

\section{Considerações Finais}

O que sabemos mediante o que aqui colocamos é que há que se questionar firmemente se o modelo de política de drogas adotado no Brasil é o mais indicado para lidar com o problema, e destacar a necessidade de levar em consideração a adoção de alternativas ao modelo atual, em respeito a seus elementos culturais, étnicos e econômicos, em vez de se manter um sistema uniforme e repressivo, que não tem atendido, em absoluto, aos objetivos a que se propôs. 
Notadamente, em países em desenvolvimento, como o Brasil, onde se constata o grande impacto social da droga e do tráfico de ilícitos e onde a violência contra minorias raciais é ainda muito forte, mostra-se urgente a crítica ao modelo atual, totalmente ultrapassado, e a busca por novas soluções. Isso inclui a necessidade de reformulação urgente do sistema internacional de controle de drogas, visando a elaboração de modelos nacionais que possam ser avaliados pelos seus bons resultados na efetivação de direitos, e não na restrição destes.

No Brasil, as perspectivas não são animadoras, diante do perfil ultraconservador do Congresso Nacional, bem como das práticas institucionais repressivas tão enraizadas no Judiciário e na população em geral, que legitimam o encarceramento como solução mágica para o crime e para o abuso de drogas.

Espera-se que o Brasil aprofunde os debates sobre o tema para tentar romper com essa tradição repressiva e violadora de direitos humanos e, dessa maneira, possa alcançar um novo patamar de país mais justo e efetivador de direitos, o que, no entanto, só será possível se modificarmos o paradigma atual. Todavia, no atual momento, além de lutarmos contra uma política de drogas proibicionista, um governo e um Congresso Nacional extremamente conservadores, ainda precisamos nos manter firmes e saudáveis em meio uma pandemia que assola milhões de brasileiros e de um governo que tão pouco se importa com a saúde de sua população, pois o chefe de Estado de nosso país, por muitas vezes, se posicionou contra o isolamento e participou de diversos atos públicos com aglomerações. Ou seja, só nos resta resistir e não desistir de, coletivamente, construirmos uma sociedade mais justa socialmente, igualitária e longe de todas as formas de opressão. Por uma sociedade sem manicômios.

\section{Referências}

AMARANTE, P. A (clínica) e a Reforma Psiquiátrica. Archivos de saúde mental e atenção psicossocial. Rio de Janeiro: Nau editora, 2003. ARBEX, L. Holocausto Brasileiro. Editora Geração editorial, São Paulo, 2013. 
BARCELLOS, W. de S.; DUARTE, M. J. de O. Política de drogas, modelos assistenciais e a rede de atenção aos usuários no Brasil: uma análise crítica. In: BARCELLOS, W. de S.; DUARTE, M. J. de O. (Orgs.). Politicas sociais brasileiras em contextos de crise: desafios contemporâneos. Belo Horizonte: Ed. UEMG, 2020.

BASAGLIA, F. Escritos selecionados em saúde mental e reforma psiquiátrica. Editora Garamond, Rio de Janeiro, 2005.

BEHRING, E. R.; BOSCHETTI, I. Política Social: fundamentos e história. São Paulo: Cortez, 2008.

BOITEUX, L. Brasil: reflexões críticas sobre uma política de drogas repressiva. In: Revista Internacional de Direitos Humanos. Revista Sur, v.12, N. 21. Ago. 2006.

BRASIL. Constituição da República Federativa do Brasil. Brasília, 1988.

. Conselho Nacional de Políticas sobre Drogas (CONAD). Resolução № 01, de 09 de março de 2018. Brasília, DF: CONAD, 2018.

. Conselho Nacional de Saúde. Recomendação 001, de 31 de janeiro de 2018. Disponível em: <https://conselho.saude.gov.br/recomendacoes/2018/Reco001.pdf>. Acesso em: 18 abr. 2021.

. Ministério da Saúde. Portaria GM/MS № 3.588, de 21 de dezembro de 2017. Brasília, DF, 2017.

DUARTE, M. J. de O. Política de Saúde Mental e Drogas: desafios ao trabalho profissional em tempos de resistência. In: Libertas, n. 2, v.18, 2018.

JUNQUEIRA. M.R; TEJADAS. S.S. Serviço Social e pandemia: desafios e perspectivas para a atuação no sociojurídico. Serv. Soc. Soc. no.140 São Paulo Jan./Apr. 2021 Epub Feb 22, 2021. Disponível em:

<https://www.scielo.br/scielo.php?script=sci_arttext\&pid=S010166282021000100101>. Acesso em: 31 mar. 2021.

MBEMBE, A. Necropolitica. Madrid: Melusina, 2011. 
. Necropolítica: una revisión crítica. In: MC GREGOR, H. C. Estética y violência: necropolitica, militarizacion y vidas lloradas. México: Universidade do México, 2012, p. 130-140.

RIBEIRO JUNIOR, A. C. As drogas, os inimigos e a necropolítica. Cadernos do CEAS, Salvador, n. 238, p. 595-610, 2016.

VASCONCELOS, E.M. Reforma Psiquiátrica, tempos sombrios e resistência: diálogos com o marxismo e o Serviço Social. Editora Papel Social, Campinas, 2016. 